boards, and makes the process of running the station very much easier. Moreover, for a small station, coal is likely to be compctitive, while in the larger sizes the arguments in favour of cxpensive nuclear power stations are compelling.

The argument has bcen further complicated, perhaps deliberately, by the suggestion that Alcan might be willing to pay back to the British Government money it borrowed during the war to build aluminium plants in Canada. The sum involved is $\mathfrak{£ 5 0}$ million, and half was to be repayed in 1971, the other half in 1974. Repayment of this debt in dollars would be welcome for the beleaguered British economy. The Alcan plan would also be welcomed by the mining industry, which is eager to find new outlets for its products. The Coal Board says that most of the coal for the Invergordon smelter would come from the north-east coal field, and possibly some might come from Scotland.

So far the other aluminium companics which put in tenders for smelters-Rio Tinto Zinc and British Aluminium-are standing by their original intention to use nuclear stations. Meanwhile Alcan has other fish to fry-it is also to build a smelter in Japan, on the island of Hokkaido. The smelter, which will have a capacity of 130,000 tons (more than twice the size of the smelter proposed for Invergordon), is expected to come into full production in 1972. Production will start in 1970, and Alcan says that the Japanese market is expanding more quickly than any other. Although the 20 per cent annual expansion experienced between 1958 and 1967 is unlikely to be maintained, a more modest rate of expansion-perhaps 10 per cent a year - should still make Japan the second largest consumer of aluminium by 1972, after the United States.

\section{Causes of Death}

THE Area Mortality volume of the Registrar General's Decennial Supplement gives an analysis of deaths in England and Wales for the five years 1959-63. With the total number of deaths in the period being just over 2.7 million, the annual death rate per thousand of the population was just over 12.5 for males and just under $11 \cdot 3$ for females. Figures known as the Standardized Mortality Ratios (SMR), which are given to aid comparisons, express the actual number of deaths as a percentage of the "expected" number. Thus for the country as a whole the SMR is 100 .

Deaths from all causes and from the sixteen most widespread diseases are first analysed into ten regions and conurbations, and then into the nature of the area, whether rural or urban of varying sizes. Then follow analyses for hospital regions, London and county boroughs and finally administrative counties, which are split into urban and rural areas. Seventeen diseases which cause fewer deaths are then listed and the figures analysed into three categories only for region, nature of area and hospital region. Separate tables are given for males and females and, as well as totals for each cause of death, the figures are split into six age groups -under 1 year, $1-4,5-14,15-44,45-64$ and 65 and over. A separate table gives infant death rates from seven different causes, as well as the number of stillbirths and the live birth rates for the various areas. For the five year period the total number of live births was just over 4 million, indicating an excess of births over deaths of about 1.3 million for the five years.
'This supplement continues the series that has been produced by the Registrar General since 1851. It also continues to show that mortality was highest in the north-western region, as was found in the 1951 supplement. In general, rural districts had the lowest death rates, but density of population did not always produce high mortality. The SMRs for Greater London were below the national average for all causes, although those for lung cancer in the area were very high.

The large number of geological, economic and social factors involved in mortality figures complicate their interpretation. Official comment on the Area Mortality supplement is therefore to be published separately.

\section{Patients in Hospital}

THERE was an increase in the number of patients discharged from British hospitals in 1964, and a decrease in the average length of stay in hospital compared with 1962 and 1963. Men and boys stayed in hospital an average length of 18.3 days in 1964; women and girls (including maternity patients) averaged just under two days less (16.7 days). Between 1962 and 1964 there was also a drop in the number of beds occupied per million population. These are somc of the findings in Part 1 of the Report on Hospital In-Patient Enquiry for the year 1964, which has just been published on behalf of the Ministry of Health and the General Register Office (HMSO, 3ls.).

The report contains detailed tables prepared from the 1964 ten per cent sample of discharges and deaths recorded by National Health Service hospitals in Fngland and Wales, except those for psychiatric, pre-convalescent and convalescent patients. The hospital in-patient enquiry has two purposes which are closely related - to provide administrative data for the hospital services in terms of diseases treated and of the characteristics of the patients who had these diseases, and to provide information which can be of help in assessing the amount, distribution and effect of illness in the community and in various sections of it. Hospitals collect all the information by completing forms for one patient in every ten on discharge or death.

The tables are a mine of information. They include analyses by sex, age, region of residence and diagnosis, and by source of admission (that is, whether from a waiting list, immediate or other type of admission) and diagnosis. Many of the tables are connected with length of stay in hospital, and from this the average number of beds used daily and in relation to the total population has been calculated. These figures are shown for diagnostic group, age, sex, marital status, region of residence and hospital department (speciality) and certain combinations of these factors. Significant conclusions could no doubt be drawn from these figures and those for 1962 and 1963 . A discussion of the tables is in fact to be published later in a separate commentary volume covering the ycars 1962 to 1964 .

An innovation in the tables is the singling out of the place where accidents happened to people admitted to hospital. Injuries, poisonings and the like are all analysed in great detail according to whether they were caused by road traffic accidents, accidents in the home, or "other" mishaps. Not surprisingly, head injuries (excluding skull fractures) account for the 
highest percentage (39.9 per cent) of the 102,830 victims of road traffic accidents who needed hospital treatment. Fractures of different parts of the body made up most of the rest of the total; burns, however, accounted for only $0 \cdot 1$ per cent of road traffic injuries. Poisons caused a high proportion of accidents in the home 33.1 per cent out of the estimated total of 133,490 home accidents noted in the enquiry. Figures are given for all kinds of poisons-even strychnine and belladonna are included in the results.

\section{Agreement Signed}

A TEOHNOLOGICAL agreement between the United Kingdom and the USSR which has been talked of for some time was signed last week by the technology chiefs of the two countries (see Nature, 216, 1060; 1967). The Russian delegation, which spent four days in London completing negotiations with the Ministry of Technology, was led by Academician V. A. Kirillin, Deputy Chairman of the Council of Ministers and Chairman of the State Committee of the Council of Ministers of the USSR for Science and Technology. Mr Anthony Wedgwood Benn, the minister, and Mr Fred Mulley, Minister of State at the Foreign Office, signed on behalf of the British Government. The agreement provides for investigation of topics of mutual interest to the two countries at all levels, and is seen as the beginning of a "special industrial relationship". Mr Wedgwood Benn hopes that each side will "discover what is interesting, and pursue it".

The ministers, or their deputies, will meet once w year to reviow the working of the agreement, with reference to the progress of scientific, technologicel and economic co-operation. Joint working parties will determine the fields for cooperation and will recommend specific subjects for investigation in the fields of research, development, technology and organization of industry. Contacts at all levels will be encouraged as a means of turning the agreement into action. Exchange visits for studies, training and consultation will be arranged. Facilitics will be provided for research and practical experience in each country and scientific and technical information will be exchanged. It is expected that licensing arrangements will be made to suit circumstances as they arise. The agreement places no limit on the joint work that can be done, as it provides for "any form of co-operation in applied science and technology as may be mutually agreed".

Five subjects which have been agreed, and are to be investigated by working groups, are educational technology, transport technology, materials research, information storage, processing and retrieval and non-conventional methods of food production. The ten items under the heading of industrial technology include the topics already being investigated by the Confederation of British Industry following the visit of a delegation to Russia last autumn.

\section{Viking Ships on the Move}

\section{from Angela Croome}

Srx years ago the Danish National Museum recovered the timbers of five 1,000-year-old Viking ships from Roskilde Fjord in an intensive and precisely calculated 3-month exercise which followed several years of underwater investigation. The ships, dated by carbon14 measurements of caulking material, were known to be expendable hulks stripped down to essentials and sunk with stones across the main navigation channel to block access to the rich settlement at the head of the fjord which later became the medieval Danish capital of Roskilde. The fjord was shallow, so that a low cofferdam was enough to enable pumping out and salvage of the timbers (see picture).

By now the first ship has completed the long and tricky "pickling" process needed to preserve its fragile timbers in air, and the work of turning these back into a ship can begin. This will take place in a specially built ship museum on the banks of the Roskilde Fjord where the first ship to complete processing is to move this week. Museum staff expect reassembly of the first ship to be completed this year when the new museum will be: opening to the public. After that, visitors can watch the other ships assembled one by one. The ship being moved to the museum this week is made up of 5,000 individual pieces of wood. These have taken from 6 months to 2 ycars to be "rehabilitated"- the waterfilled gaps must be filled with ethyl-glycol so that the wood, saturated for a thousand years in water, will not shrink when exposed to air. A cycling process in solution tanks heated to $60^{\circ} \mathrm{C}$ has been employed and has taken longer than originally expected. It may yet be: a vear or so before the remaining ships are ready for

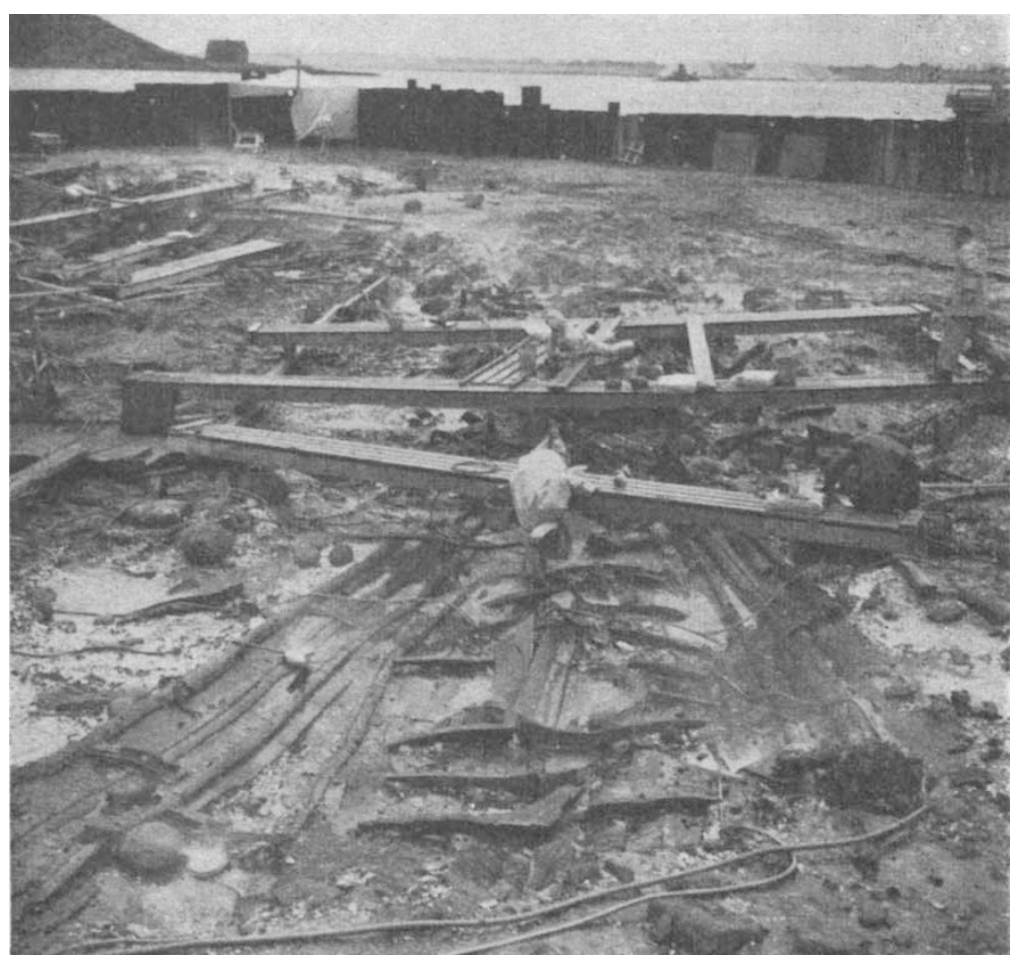

The skeleton of one of the five tenth-century Viking ships emerges from the mud of Roskilde Fjord. When this picture was taken, in August 1962, the work of clearing the ships of mud and stones was two-thirds complete. Garden sprinklers are in use to keep the exposed wood damp. 